\title{
Palladium recovery through membrane capacitive deionization (MCDI) from metal plating wastewater
}

David Inhyuk Kim ${ }^{\mathrm{a}, \mathrm{b}}$, Gimun Gwak ${ }^{\mathrm{b}}$, Pema Dorjia ${ }^{\mathrm{a}}$ Di He ${ }^{\mathrm{c}, \mathrm{d}}$ Sherub Phuntsho ${ }^{\mathrm{a}}$, Seungkwan Hong ${ }^{\mathrm{b}}$, and Hokyong Shon ${ }^{\mathrm{a}, *}$

${ }^{\mathrm{a} C e n t r e}$ for Technology in Water and Wastewater, School of Civil and Environmental Engineering, University of Technology, Sydney (UTS), 15 Broadway, Ultimo NSW 2007, Australia ${ }^{\mathrm{b}} \mathrm{School}$ of Civil, Environmental \& Architectural Engineering, Korea University, 145, Anam-ro, Seongbuk-Gu, Seoul, 02841, Republic of Korea

'Institute of Environmental Health and Pollution Control, Guangdong University of Technology, 100 Waihuan Xi Road, Panyu District, Guangzhou 510006, China

${ }^{\mathrm{d}}$ Guangzhou Key Laboratory of Environmental Science and Engineering. Guangdong University of Tehcnology, 100 Waihuan Xi Road, Panyu District, Guangzhou 510006, China

\footnotetext{
* Corresponding author. E-mail address: Hokyong.Shon-1@uts.edu.au
}

\begin{abstract}
The potential application of membrane capacitive deionization (MCDI) for recovery of palladium $(\mathrm{Pd})$ ions from catalyst solution wastewater generated from plating industry was investigated in this study. Several major issues were explored in this work to verify the
\end{abstract}


suitability of MCDI for Pd recovery from a practical perspective: adsorption and desorption efficiencies, desorption mechanisms into high concentration of $\mathrm{Pd}$ concentrate, and its sustainability in long-term operation. The lab-scale MCDI operation achieved satisfactory and highly competitive Pd removal (99.07-99.94\% removal with 1.42-1.52 of Pd selectivity over ammonium ions) showing that $\mathrm{Pd}$ can be effectively collected from plating industry wastewater. High concentration of Pd concentrate $(64.77$ and $919.44 \mathrm{mg} / \mathrm{L}$ of Pd from the 10 and $100 \mathrm{mg} / \mathrm{L}$ Pd containing catalyst solution, respectively) was obtained through successive five operation cycles of adsorption/desorption phases. However, it is significant to note that the desorption efficiency was inversely proportional to the concentration of Pd concentrate which is likely due to the Pd ions discharged from carbon electrode toward Pd solution against the enhanced concentration gradient. The long-term operation results suggest that scaling could reduce the MCDI efficiency during Pd recovery $(0.17 \%$ decrease in Pd removal for every cycle on average) and hence may require adequate electrode cleaning regime.

Keywords: Membrane capacitive deionization (MCDI); Electrosorption; Palladium concentration; Ion desorption; Wastewater from plating industry 


\section{Introduction}

As a result of large-scale exploitation of minerals in contemporary industry and the increasing concerns over environmental issues caused by wastes in electrical and electronic equipment (WEEE), reusing and recycling precious metals from secondary resources (i.e., industrial wastewater) are deemed to be important for those sustainable utilization. ${ }^{1-2}$ With the significant increase in amount of WEEE and the ever-growing concerns of contamination by toxic and precious metal sources, a "WEEE directive" has been issued by The European Union, forcing EEE industries to take responsibility for the collection of recovery and recycling of WEEE. ${ }^{3}$ Printed circuit board (PCB), which is a key part of electronic devices, has been gaining interests as one of the largest source of heavy metals.

In PCB manufacturing processes, palladium $(\mathrm{Pd})$ complexes are widely used as catalysts to activate electro- and electroless-plating processes, which are regarded as very important steps for fabricating fine products. Electrowinning, the reclamation of used Pd solution from the plating process by electrodepostion of metals from wastewater, is known as the most effective and commonly used metal recovery system. ${ }^{4-5}$ However, recovering the wasted Pd by electrowinning is unfeasible due to its limited recovery and energy-efficiency especially at low concentration, and a significant amount of low Pd concentration wastes is being disposed by being diluted with other wastewater sources to satisfy the regulations of industrial wastewater discharge. Several new technologies, such as precipitation, solvent extraction, conjugate absorbents and ion exchange resins have been studied as an alternative to the electrowinning for high Pd recovery with better-efficiency. ${ }^{6-9}$ Concentrating the Pd-containing solution prior to electrowinning with an energy-efficient technology is expected to be one of the most possible option to improve the energy-efficiency and total $\mathrm{Pd}$ recovery rate. Therefore, concentrating the Pd containing wastewater from plating industry by means of capacitive deionization (CDI) with low energy use could be done to facilitate feasible and sustainable Pd recovery.

CDI is a technology that has been mainly applied for desalination to produce pure water through the extraction of charged species from water by applying an electrical potential difference over two porous electrodes. It has been one of the most alternative and feasible technology in recent years for sustainable fresh water production from unconventional water resources. ${ }^{10-11}$ This electrosorption process has especially shown to have better energyefficiency than RO for deionization at low salt concentration levels water (i.e., salt concentration $\leq 30 \mathrm{mM}$ ), such as municipal wastewater and brackish water. ${ }^{11}$ Previous 
researches on development of advanced materials of electrode, effective process designs, and energy recovery have drastically improved this process, making this technology feasible for potable water production. ${ }^{12-14}$

Aside from the use of CDI for water production, this technology has also been further studied for other applications including recovery of resources from the water. ${ }^{15-28}$ Since there is a rising global demand for vastly-depleting natural resources and nutrients, reclaiming valuable resources such as nitrogen, phosphorus, and mineral resources from municipal wastewaters and saline water sources has emerged as a great environmental solution. ${ }^{29-31}$ Since the CDI is based on the principle of ions and charge separation, it has shown to be potentially effective in the recovery of charged resources by highly removing/concentrating or selectively collecting present in minute amounts in low salinity water.

There are several studies that investigated the suitability of CDI for the recovery of nutrients and minerals. Especially, most CDI studies have noted on the recovery of nitrogen ${ }^{15-}$ 19 and phosphorus ${ }^{20-21}$ from municipal wastewaters as one of the most possible applications. Works in the copper removal revealed that $\mathrm{CDI}$ can be used to extract $\mathrm{Cu}^{2+}$ from wastewater with high selectivity over $\mathrm{NaCl}$ and natural organic matter (NOM) in a competitive environment. ${ }^{22-23}$ Studies on lithium recovery using CDI show excellent removal performance with faster adsorption/desorption than conventional lithium recovery process, and durability over several adsorption and desorption cycles. ${ }^{24-26}$ Binder-free carbon nanotube (CNT) electrode was found to provide a much increased electrochemical surface area, leading to enhanced removal of $\mathrm{Cr}^{\mathrm{VI}}$ and $\mathrm{Cr}^{\mathrm{III}}$ ions, ${ }^{27}$ whereas $\mathrm{Pb}^{2+}$ ions were more easily captured by an air-plasma treated CNT electrode in another study. ${ }^{28}$

The main objective of this work is to investigate the potential application of CDI for the recovery of Pd resources from the plating industry wastewater. The performances of the CDI for Pd recovery under different feed conditions and the influence of various operating parameters were studied using lab-scale membrane CDI (MCDI) unit, which is currently one of the most advanced systems in this field. ${ }^{32}$ The issues of the MCDI performances including the adsorption and desorption efficiencies in long-term operations, and its improvement to attain higher concentration of $\mathrm{Pd}$ concentrate were discussed. Following up the long-term runs, the sustainability of CDI as a recovery process has been discussed through investigating the scaling behavior caused by Pd. Lastly, we introduced a new process for the efficient Pd recovery from plating industry wastewater integrating CDI stage, and also suggested 
improvements of CDI for its enhanced sustainability and feasibility through simplifying the Pd recovery process.

\section{Experimental}

Model palladium and palladium catalyst solution for electroless plating

Tetraamminepalladium(II) sulfate (Alfa Aesar, MA) was chosen as representative Pd species, since it can be found in Pd catalyst solutions. Three different concentrations of Pd in model solution were used for the MCDI tests: 1,10 , and $100 \mathrm{mg} / \mathrm{L}$, which are within the range of actual Pd catalyst wastewater concentration observed in the PCB manufacturing process. A bulk palladium catalyst solution for electroless plating was also provided by MSC Co., Ltd (Republic of Korea) to assess the performance of MCDI as a real palladium recovery process. The major compositions of the Pd catalyst solution under different concentrations of Pd species are listed in Table 1. As oxidation of carbon electrodes caused by dissolved oxygen in feed water is regarded to be insignificant in the MCDI system, the de-aeration of the Pd feed solution was not performed in this study. ${ }^{33}$

TABLE 1. Major characteristics of 1,10 , and $100 \mathrm{mg} / \mathrm{L}$ of diluted Pd catalyst solutions.

\begin{tabular}{cccc}
\hline \multirow{2}{*}{ Parameter } & \multicolumn{3}{c}{ Pd catalyst solution } \\
\cline { 2 - 4 } & $1 \mathrm{mg} / \mathrm{L}$ of $\mathrm{Pd}$ & $10 \mathrm{mg} / \mathrm{L}$ of $\mathrm{Pd}$ & $100 \mathrm{mg} / \mathrm{L}$ of $\mathrm{Pd}$ \\
\hline Total dissolved solids $(\mu \mathrm{S} / \mathrm{cm})$ & 12.23 & 46.4 & 337 \\
$\mathrm{SO}_{4}{ }^{2-}(\mathrm{mg} / \mathrm{L})$ & 0.90 & 9.03 & 90.27 \\
$\mathrm{NH}_{4}{ }^{+}(\mathrm{mg} / \mathrm{L})$ & 4.36 & 13.93 & 37.04 \\
$\mathrm{pH}$ & 8.22 & 9.63 & 10.32 \\
\hline
\end{tabular}

\section{Carbon electrodes and ion exchange membranes}

Two porous carbon electrodes manufactured by Siontech Co. (Republic of Korea) were used. The electrodes consisted of a graphite sheet body coated with activated carbon P-60 (Kuraray Chemical Co., Japan) and PVDF (Inner Mongolia 3F-Wanhao Fluorine Chemical Co. Ltd., China) blended carbon slurry. The total carbon mass on each $10 \times 10 \mathrm{~cm}^{2}$ sized electrode was reported to be $0.8 \mathrm{~g}$. Commercial anion and cation exchange membranes (Neosepta AFN and $\mathrm{CMB}$, respectively) were obtained from Astom Corporation (Japan).

Bench-scale MCDI setup 
The MCDI tests were carried out in a bench-scale flow-through system as depicted in our previous study. ${ }^{34}$ The dimensions of the rectangular feed channel of the test cell were $10 \mathrm{~cm}$ in width and $10 \mathrm{~cm}$ in length, providing an effective ion adsorption/desorption area of $100 \mathrm{~cm}^{2}$. There were two carbon electrodes placed within the test cell, whereas the anion and cation exchange membranes were inserted between those two electrodes. A non-electrically conductive nylon spacer was placed between the two ion exchange membranes to ensure the water flow and prevent short circuit. A $1 \mathrm{~cm}$ diameter sized hole was punched in the center of carbon electrodes, ion exchange membranes, and a nylon spacer to enable the solution to be completely in contact with the electrodes and provide flow within the entire system cell. ${ }^{35}$

$100 \mathrm{~mL}$ of feed solution was recirculated throughout the MCDI system with the flow rate of $30 \mathrm{~mL} / \mathrm{min}$ by a peristaltic pump (Cole-Palmer, IL). The electrical potential supplied through the MCDI test unit was adjusted at a constant level by a potentiostat, WPG-100 (WonATech Co., Republic of Korea). The MCDI system was stabilized at the desired voltage after the feed water was circulated by repeating 5 cycles of $2 \mathrm{~min}$ for ion adsorption followed by $2 \mathrm{~min}$ of ion desorption. All the tests were carried out in duplicate.

\section{Multiple cycles operation for concentration of Pd}

The five or ten cycles operation procedure of MCDI is depicted in Figure $1.100 \mathrm{~mL}$ feed solution containing $100 \mathrm{mg} / \mathrm{L} \mathrm{Pd}$ circulated through the MCDI system for $8 \mathrm{~min}$ at $0.9 \mathrm{~V}$ adsorption condition. To desorb the Pd ions attached onto the carbon electrode, $50 \mathrm{~mL}$ of fresh DI water was made to circulate through the system at the same conditions as adsorption by applying reverse potential. The desorbed Pd ions from the MCDI system were collected onto the concentrate solution after the primary desorption process for all cycles. To completely remove residual $\mathrm{Pd}$ ions remaining on the carbon electrode, an additional desorption step (secondary desorption) in the MCDI system was carried out with newly replaced $50 \mathrm{~mL}$ fresh DI water at the same time and electric potential conditions by applying reverse potential. The water containing the residual Pd ions was then discarded. These adsorption, desorption, and secondary desorption processes were performed for five or ten cycles, with $100 \mathrm{~mL}$ of fresh feed solution and $50 \mathrm{~mL}$ of $\mathrm{Pd}$ concentrated water for each test. Complete desorption of ions from the electrodes was ensured by employing a further desorption step for 20 min at $-1.2 \mathrm{~V}$ after the secondary desorption in each cycle, and thereby no discharge of ions during this step was detected by a conductivity meter confirming that there are no remaining ions that could be released by electrical force. The mass balance on the adsorbed and desorbed Pd ions was also 
calculated to make sure that ions were completely released at the end of each cycle.
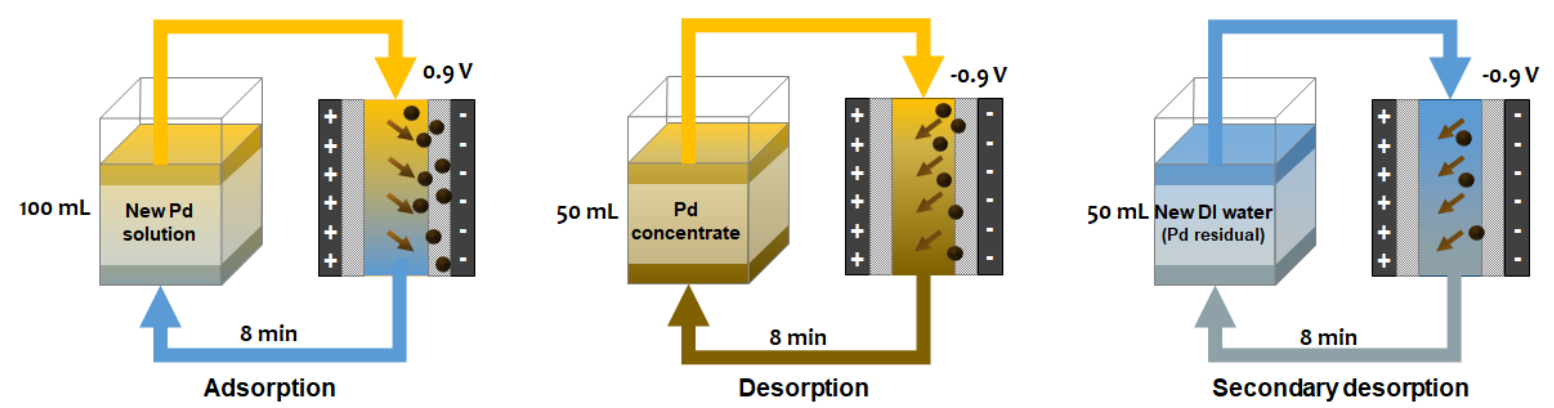

Figure 1. The protocol for MCDI test with multiple cycles.

After the long-term operation, both anode and cathode, and anion and cation exchange membranes in the MCDI system were disassembled, pre-rinsed with DI and followed by desiccation for over $24 \mathrm{hr}$ to ensure complete drying of the samples. Then the surface of samples was analyzed by scanning electron microscopy (SEM) and energy-dispersive spectroscopy (EDS) in order to investigate the effect of long-term operation on MCDI performances.

\section{Measurement of water quality}

The Pd concentrations of feed, permeate and concentrate waters were analyzed by inductively coupled plasma-mass spectrometer (ICP-MS), NExon 300D ICP-MS (Perkin Elmer Co., MA). The water samples were diluted 100 times for accurate quantification of palladium ion. The calibration of ICP-MS was performed before measurement by external calibration with deionized water and 4 standard palladium solutions $(0.625,1.25,2.5$ and 5 $\mathrm{mg} / \mathrm{L})$.

\section{Results and discussion}

Basic performance of MCDI for Pd collection 
To assess the capacity of MCDI in Pd recovery and optimize operating conditions, the Pd removal in this system was tested under varying operating conditions such as applied voltage, duration and Pd concentrations with or without other ions in the adsorption stage.

\section{Pd removal in MCDI under different operating conditions}

The basic removal of Pd by MCDI was first evaluated using the synthetic Pd solution to observe the effect of voltage and time on Pd removal only, without interference of other coexisting ions. Figure 2 shows the Pd removals from the $100 \mathrm{mg} / \mathrm{L} \mathrm{Pd}$ solution at four different potentials during adsorption, ranging from 0.3 to $1.2 \mathrm{~V}$ applied voltage. As shown in the results, the MCDI process exhibited a very high efficiency for Pd removal throughout all the applied voltages. The removal efficiency and specific removal was $98.38 \%$ and $11.99 \mathrm{mg} / \mathrm{g}$, respectively, even at a small applied voltage of $0.3 \mathrm{~V}$, reaching $99.84 \%(12.18 \mathrm{mg} / \mathrm{g}$ specific removal) at $1.2 \mathrm{~V}$ when the adsorption was operated for $8 \mathrm{~min}$. The highly efficient adsorption of Pd ions on carbon electrode might be driven by both electrosorptive and physical adsorption, such as the sorption behavior of other heavy metal ions in MCDI. ${ }^{36} \mathrm{~A}$ further adsorption test was carried out employing $0 \mathrm{~V}$ for 8 min using the synthetic Pd solution containing $100 \mathrm{mg} / \mathrm{L}$ of Pd to clarify the physisorption behavior during Pd removal in MCDI (Fig. S1). A significant amount of $\mathrm{Pd}$ removal attained by physisorption (24.88\%) implies that both electrosorption and physisorption play important roles adsorbing the Pd species during Pd removal in MCDI, leading to high Pd removal. However, this unanticipated behavior brings concern of deterioration of performance of MCDI. The hampered performance of carbon electrodes caused by physical adsorption on the carbon surface will be discussed further in the following sections.

It appears that the optimum voltage for Pd removal by MCDI is about $0.9 \mathrm{~V}$ achieving a removal efficiency of $99.80 \%(12.17 \mathrm{mg} / \mathrm{g}$ specific removal $)$ under the operation of MCDI for $8 \mathrm{~min}$, and applying voltage higher $1.23 \mathrm{~V}$ would not only increase energy input but also contribute to water splitting. This trend of removal could be also found in the MCDI runs with different charging times. The Pd removal at different operation times for $0.9 \mathrm{~V}$ applied voltage in Figure 2 shows that the Pd ions were highly extracted by MCDI system achieving $96.76 \%$ of Pd removal (11.80 mg/g specific Pd removal) within just 2 min and above 99.06\% (12.08 $\mathrm{mg} / \mathrm{g}$ ) in about $4 \mathrm{~min}$. To sum up, the operation of MCDI at $0.9 \mathrm{~V}$ for $8 \mathrm{~min}$ is likely to be the optimum condition for Pd recovery. Similar observations were made in the previous work optimizing the salt adsorption rate in MCDI, which showed similar trends with different 
operating time and voltage. ${ }^{37}$

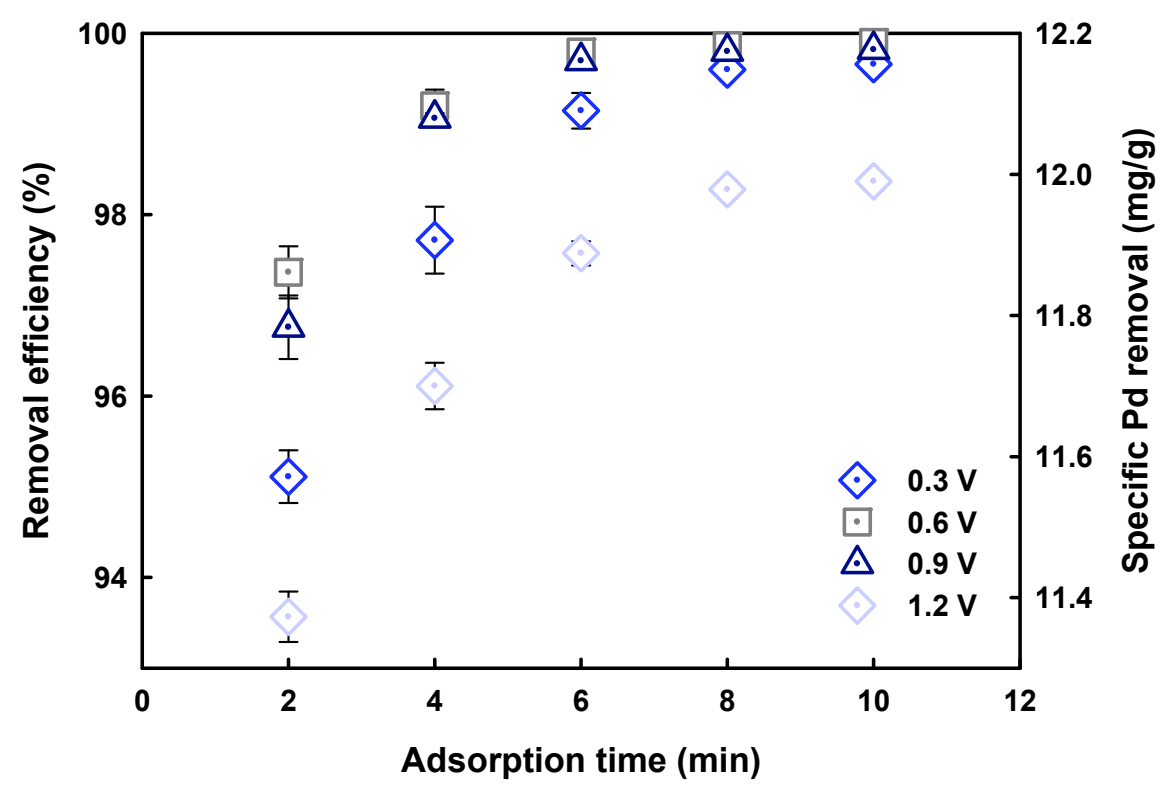

Figure 2. Pd removal using the synthetic solution containing $100 \mathrm{mg} / \mathrm{L}$ of palladium under different potentials ( 0.6 to $1.2 \mathrm{~V}$ ) operating times ( 2 to $8 \mathrm{~min}$ ) in adsorption step.

\section{Effect of feed water concentration and composition on Pd removal}

Figure 3a presents the removal of Pd ions from the synthetic Pd and Pd catalyst solutions as a function of $\mathrm{Pd}$ concentration in feed water. The Pd removals of both the synthetic and catalyst solutions were consistently more than $99.74 \%$ for Pd concentration between 5 and 100 $\mathrm{mg} / \mathrm{L}$. Meanwhile, the Pd ions indicated slightly lower removal at low feed concentration: 98.65 and $99.49 \%$ from synthetic solution and 98.99 and $99.59 \%$ from catalyst solution, for feed solutions containing 1 and $2 \mathrm{mg} / \mathrm{L}$ of $\mathrm{Pd}$, respectively. This is due to the fact that, lower TDS or Pd concentration has poor electrical conductivity and higher resistance because of which limits the movement and electrosorption of Pd ions but the electrosorption linearly increases with the feed concentrations or feed electrical conductivity. ${ }^{38-39}$ However, when the feed TDS increases more than $150 \mathrm{mg} / \mathrm{L}$ of $\mathrm{Pd}$, the sorption efficiency stabilizes or gradually decreases.

The removal of Pd in the catalyst solution was slightly lower than that in the synthetic Pd solution, within the range of 5 to $150 \mathrm{mg} / \mathrm{L}$ of $\mathrm{Pd}$ in feed solution. The lower Pd removal could 
be explained due to competitive adsorption from the several other ions present in the plating feed solution, such as ammonium. ${ }^{36,40}$ The ammonium and other minor ions present in the plating solution would competitively occupy the pore space within the carbon electrode, resulting in the decreased rate of Pd removal. However, it should be noted that the Pd ions were still highly removed by MCDI even in the presence of other ions in the catalyst solution. This is likely due to the selectivity preference for Pd ions in feed water during MCDI, as shown in Figure $3 b$. The ion selectivity during Pd recovery via MCDI from Pd catalyst wastewater was ranged from 1.42 to 1.52 as the $\mathrm{Pd}$ concentration in the feed solution increased from 1 to 100 $\mathrm{mg} / \mathrm{L}$. In general the ion selectivity during the electrosorption process is strongly dependent on the initial concentration, ionic charge valency, and hydrated radius of ions. ${ }^{40}$ Firstly, the ions with high concentration is preferentially adsorbed by the carbon electrode. More specifically, cations of higher valence are energetically favorable to screen the surface charge of electrodes. On account of the governing number of $\mathrm{Pd}$ ions contained in the catalyst solution and those higher charge (divalent) than ammonium and other ions, Pd was the most preferred species to be collected by the carbon electrode. And the selectivity was shown to be increased as the ratio of $\mathrm{Pd}$ over $\mathrm{NH}_{4}{ }^{+}$increased in higher concentration of catalyst solution.

Furthermore, Pd ions were shown to be more adsorbed in the catalyst solution under low concentration such as 1 and $2 \mathrm{mg} / \mathrm{L}$ of $\mathrm{Pd}$. This is because the co-existing ammonium ions increases the total ion mobility toward the carbon surface, leading to higher adsorption capacity under low TDS condition. Since the addition of other ions in Pd catalyst solution offers slightly higher TDS in the low concentration feed water, the adsorption rate reaches higher than that of the synthetic Pd solution. This clearly shows that the co-existence of other ions such as ammonium in the catalyst solution could rather support the Pd removal performance of MCDI than competitively taking place of the pore and surface of electrode.

Therefore, it can be concluded that Pd could be sufficiently extracted through MCDI, and an outstanding Pd removal could be accomplished even though other co-ions existing in the $\mathrm{Pd}$ catalyst solution affect the efficiency of the process by competitive adsorption behavior. It is generally known the removal efficiencies of ions involved in the feed solution can be influenced by the initial $\mathrm{pH}$ of feed water due to adsorption of hydrogen and hydroxide ions on the surface of electrodes. ${ }^{41}$ In our study, however, $\mathrm{pH}$ of the feed solution did not play a significant role in the $\mathrm{Pd}$ removal though the initial $\mathrm{pHs}$ of catalyst solutions involving 10 and $100 \mathrm{mg} / \mathrm{L}$ of Pd were 9.63 and 10.32, respectively. 

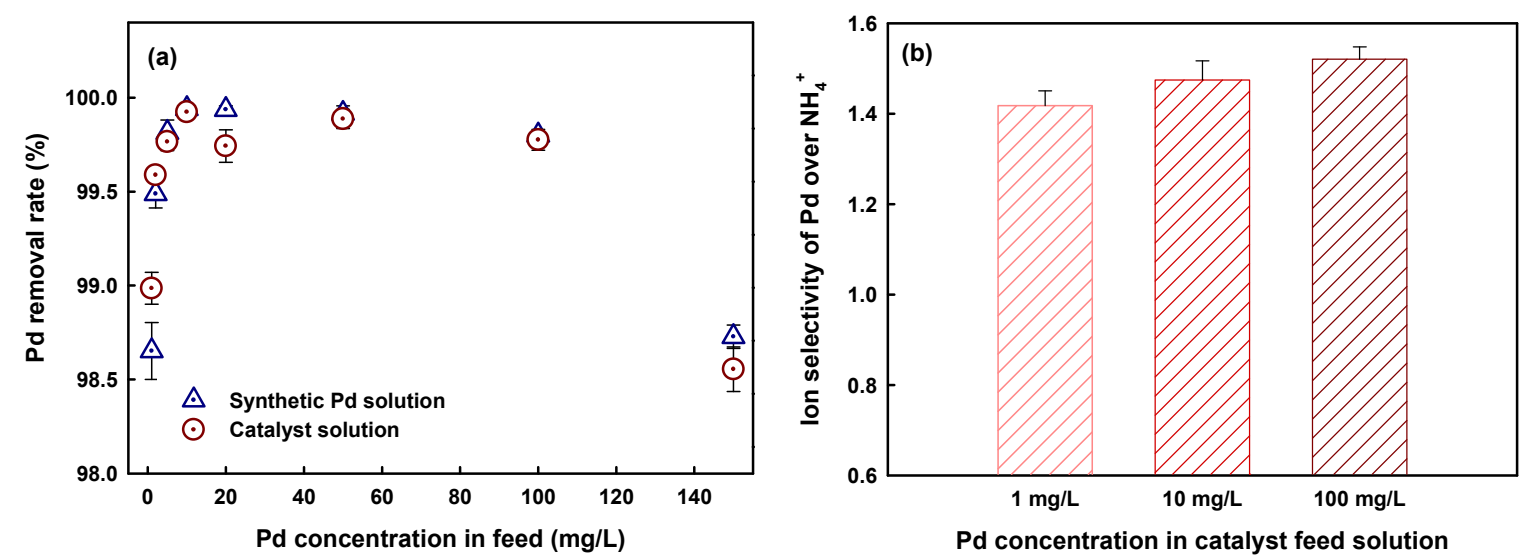

Figure 3. (a) Pd removal in synthetic Pd and Pd catalyst solutions containing 1, 10, and 100 $\mathrm{mg} / \mathrm{L}$ of $\mathrm{Pd}$, and (b) the corresponding ion selectivity of $\mathrm{Pd}$ over $\mathrm{NH}_{4}{ }^{+}$for $\mathrm{Pd}$ removal from $\mathrm{Pd}$ catalyst solution. The electrosorption was conducted at $0.9 \mathrm{~V}$ for $8 \mathrm{~min}$.

Five cycles operation of MCDI to obtain high Pd concentration

Enhancing Pd concentration through multiple MCDI adsorption and desorption cycles

The adsorption/desorption in MCDI was repeated for five cycles to capture Pd ions into the concentrate using a mixture of desorbed solution and original Pd feed solution. Figure 4 shows that the Pd concentration increases linearly in the concentrate solution after each cycle for initial feed Pd catalyst solutions containing 1, 10, and $100 \mathrm{mg} / \mathrm{L}$ of Pd in Figures $4 \mathrm{a}, \mathrm{b}$ and c, respectively. As shown in Fig 4a, the concentration of collected Pd ions in the concentrate after the $5^{\text {th }}$ MCDI cycle reached to $925.48 \mathrm{mg} / \mathrm{L}$, suggesting that MCDI could successfully recover and concentrate $\mathrm{Pd}$ ions. Theoretically, the Pd concentration in the concentrate was supposed to be $997.76 \mathrm{mg} / \mathrm{L}$ assuming a fixed $\mathrm{Pd}$ removal of $99.78 \%$ and the adsorbed ions on the carbon electrodes were completely discharged into the concentrate during the first desorption phase. Perhaps this slightly lower experimentally collected Pd ions in the concentrate is likely due to experimental errors.

Figure $4 \mathrm{~b}$ and $\mathrm{c}$ also show the potential of MDCI in concentrating Pd ions from a feed with very low Pd concentrations to achieve higher Pd concentration such as in Figure 4a, although MCDI has to be operated for significantly more cycles. After five cycles, the Pd concentration in the concentrate reached to $66.28 \mathrm{mg} / \mathrm{L}$ for $10 \mathrm{mg} / \mathrm{L}$ of Pd catalyst solution (Figure $4 \mathrm{~b}$ and $5.95 \mathrm{mg} / \mathrm{L}$ for $1 \mathrm{mg} / \mathrm{L}$ of $\mathrm{Pd}$ containing feed solution). These results show MCDI can adequately recover Pd ions from low feed concentration solutions. However, it is significant to note that 
the Pd ions in the concentrate did not increase linearly with the MCDI cycles as observed in Figure 4a. In fact a somewhat logarithmic increase was observed with repeated cycles. For example, when the MCDI was operated with $10 \mathrm{mg} / \mathrm{L}$ of Pd catalyst solution, $19.36 \mathrm{mg} / \mathrm{L}$ of $\mathrm{Pd}$ was desorbed and collected in the $1^{\text {st }}$ cycle, while this reduced to only $4.27 \mathrm{mg} / \mathrm{L}$ of $\mathrm{Pd}$ in the $5^{\text {th }}$ cycle. Likewise for $1 \mathrm{mg} / \mathrm{L}$ of Pd catalyst feed solution, $1.91 \mathrm{mg} / \mathrm{L}$ of Pd was desorbed in the $1^{\text {st }}$ cycle against $0.40 \mathrm{mg} / \mathrm{L}$ in the $5^{\text {th }}$ cycle. Assuming a stable adsorption and full regeneration in the desorption step throughout the cycles, the Pd concentration in the concentrate was expected to be 99.92 and $9.90 \mathrm{mg} / \mathrm{L}$ after the five cycles for 10 and $1 \mathrm{mg} / \mathrm{L} \mathrm{Pd}$ catalyst feed solutions, respectively. The apparent decrease in the desorption of Pd ions from the electrodes in the successive MCDI cycles shows that the desorption efficiency was deteriorated and this MCDI process would hardly concentrate the Pd species in wastewater under very low concentration in feed solution such as $1 \mathrm{mg} / \mathrm{L}$, resulting in unfeasible $\mathrm{Pd}$ recovery.
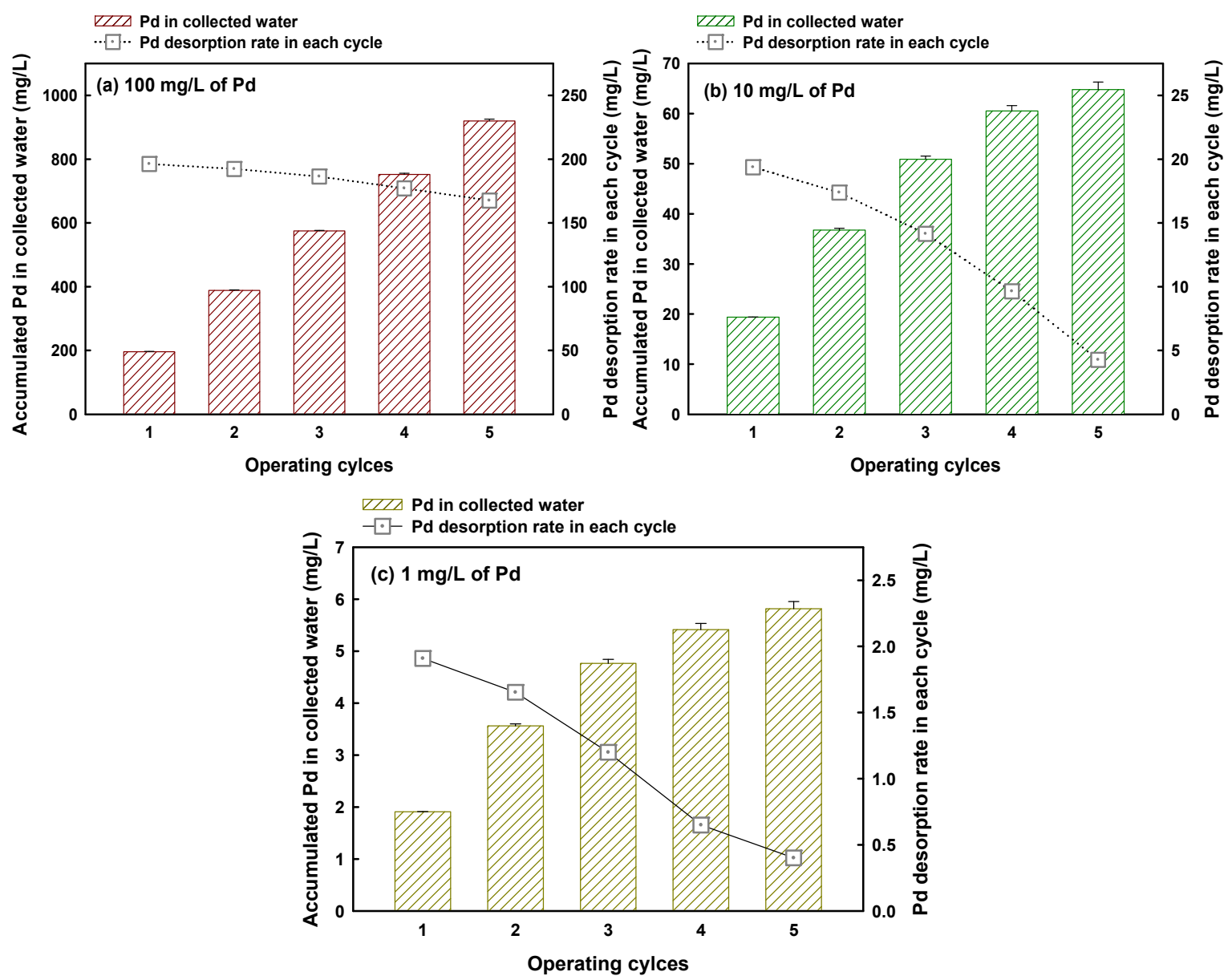

Figure 4. Concentration of Pd in concentrate solution after desorption of ions from the carbon electrodes. After adsorption of ions from new catalyst solutions containing (a) 1, (b) 10, and 
(c) $100 \mathrm{mg} / \mathrm{L}$ of $\mathrm{Pd}$, the adsorbed ions on the electrode surface were discharged in the concentrate water for $8 \mathrm{~min}$ at $0.9 \mathrm{~V}$. New feed solution was then replaced to initiate another $\mathrm{Pd}$ recovery cycle, whereas the concentrate solution was kept being used over every cycle.

\section{Effect of concentration of concentrate solution on Pd desorption efficiency in MCDI}

After every adsorption/desorption cycle at $-0.9 \mathrm{~V}$ for $8 \mathrm{~min}$, a secondary desorption step was further conducted and ions were released in a newly replaced $50 \mathrm{~mL}$ of DI water in each cycle at the same operating condition to unload any residual ionic species that probably still remained on the electrode. Figure 5 presents the concentration of further desorbed Pd into the DI water in each cycle termed in this study as "residual water". The number of additionally discharged Pd ions in the secondary desorption increased with the number of MCDI cycles, clearly indicating that the Pd ions were not completely freed from the carbon electrode during the primary desorption stage, whereas this system showed a fairly stable adsorption performance over every cycle. There are several possibilities that caused degraded desorption performance with the repeated cycles of MCDI, such as electro-oxidation, physical adsorption of ions, and scale formation. ${ }^{36,42-43}$ However, those reasons seem not to be the main cause of the significantly reduced desorption efficiency with the repeated cycles in this study, whereas the adsorption capacity of the carbon electrode was quite stable. The desorption efficiency in the primary desorption step in each cycle was notably decreased as the concentration of the $\mathrm{Pd}$ concentrate increased with repeated cycles. Most of the unreleased ions were quickly released in DI water in each secondary desorption step implying that this incomplete discharge of the ions in the first desorption phase is presumably owing to the effect of enhanced ionic concentration of the concentrate solution as explained by the Gouy Chapman Theory. ${ }^{44}$ Theoretically the electrosorptive capacity of the carbon electrodes in CDI is significantly affected by the electrical double-layer (EDL) capacity. ${ }^{38}$ Based on the Gouy Chapman Theory, the electrolyte concentration in the aqueous solution is one of the major factors determining the EDL capacity on the carbon electrode surface in CDI. ${ }^{45-46}$

Inversely, the increasing electrolyte concentration of the concentrate solution after each successive cycle leads to a lower or reverse ion concentration gradient between the carbon electrode and water media, disturbing the ion desorption from the porous carbon electrode surface. Since the concentration of concentrate solution increased as the operation cycle was repeated, the ions captured from the carbon electrode would be hardly released into the concentrate during the desorption stage, leading the $\mathrm{Pd}$ ions adsorbed on the carbon surface to be remained. The concentrate solution approaches saturation, and the lower or reverse 
concentration gradient is detrimental to desorption. For both desorption and adsorption, a higher concentration gradient is preferred to act as the driving force to overcome resistance to mass transfer of metal ions between the electrode and the solution ${ }^{47}$. This incomplete desorption behavior could also be found in a previous study which investigated the effect of concentration of concentrate on desorption performance of CDI. ${ }^{48}$
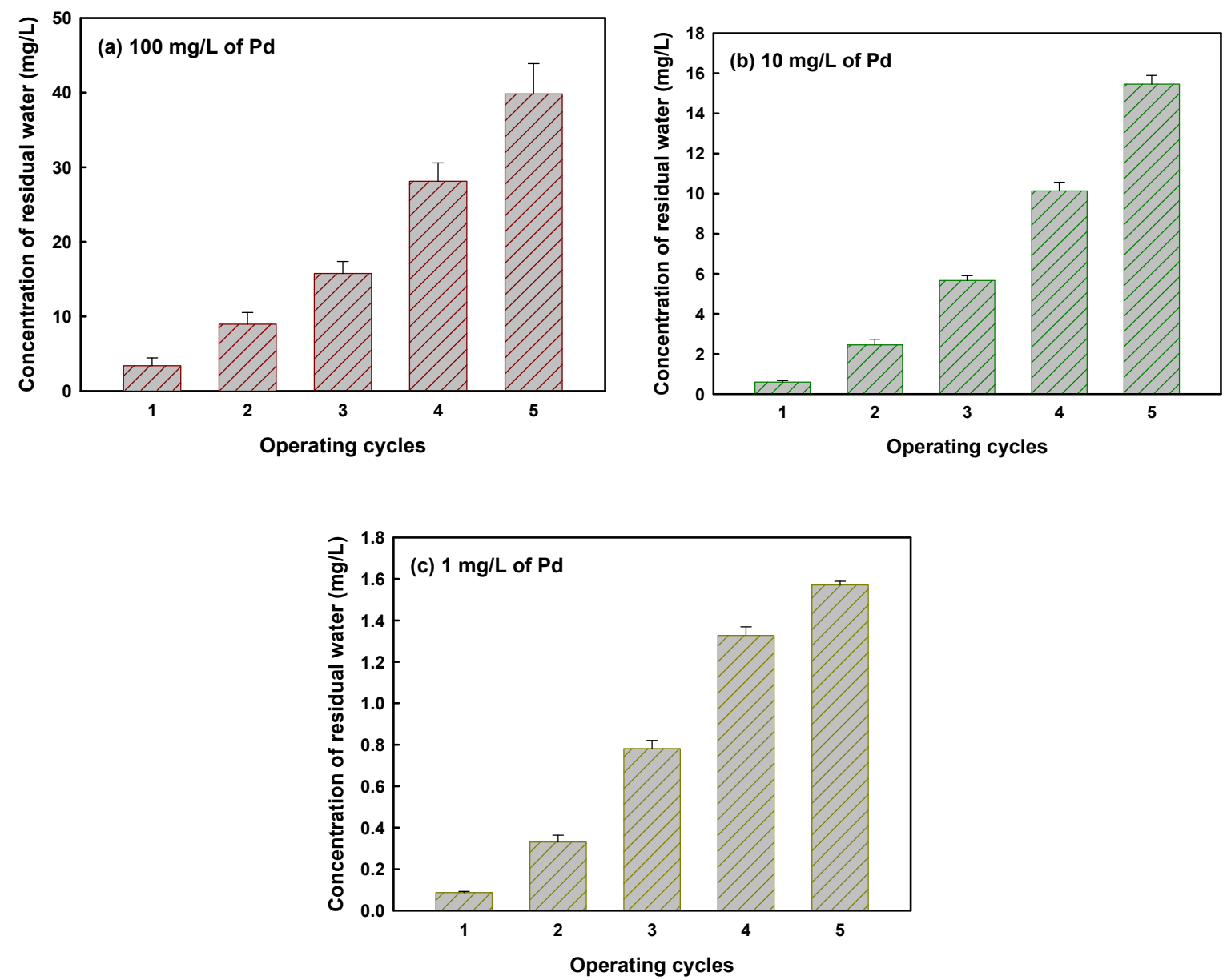

Figure 5. Concentration of $\mathrm{Pd}$ in residual solution after secondary desorption in each cycle. After adsorption/desorption using new catalyst solutions containing (a) 1, (b) 10, and (c) 100 $\mathrm{mg} / \mathrm{L}$ of $\mathrm{Pd}$, the remained ions on the electrode surface was further released in a new DI water (residual water) for $8 \mathrm{~min}$ at $0.9 \mathrm{~V}$. New feed solution was then replaced to initiate another Pd recovery cycle, whereas the concentrate water was kept being used over every cycles. New DI water was then replaced to measure the concentration of residual water after each cycle.

Enhancing desorption efficiency through increasing desorption time or applied potential for higher Pd concentration 
As observed in Section 3.2.2, adsorbed Pd ions were not completely released during each primary desorption stage as the Pd concentrations were increased in the successive MCDI cycles. This section investigates how the two main operating parameters: desorption time and applied voltage affect the concentration rate of Pd ions in the concentrate water (Figure 6). The results shows the final Pd concentration in the concentrate after the $5^{\text {th }}$ cycle using an original catalyst solution of $100 \mathrm{mg} / \mathrm{L}$ of $\mathrm{Pd}$ where adsorption was performed at $0.9 \mathrm{~V}$ for $8 \mathrm{~min}$ and desorption was conducted with different potentials ( -0.8 to $-1.2 \mathrm{~V}$ ) and times (6 to $12 \mathrm{~min}$ ). Figure $6 \mathrm{a}$ shows that, the concentration of $\mathrm{Pd}$ in the concentrate increased from $918.2 \mathrm{mg} / \mathrm{L}$ at $8 \mathrm{~min}$ desorption time to just $920.07 \mathrm{mg} / \mathrm{L}$ at $12 \mathrm{~min}$. This indicates increasing desorption time longer than $8 \mathrm{~min}$ insignificantly enhances the concentration of Pd. However, a slight increase of $\mathrm{Pd}$ concentration in concentrate water was observed when a higher potential is used as shown in Figure $6 \mathrm{~b}$ where the Pd concentrate increased from 919.44 at $0.9 \mathrm{~V}$ to $929.75 \mathrm{mg} / \mathrm{L}$ at -1.2 $\mathrm{V}$. The desorption process generally proceeds rapidly and the majority of the adsorbed ions usually should be desorbed within about 2 min of applying a reverse potential, ${ }^{35}$ and thus, the increased desorption time insignificantly improved the efficiency of Pd collection in the concentrate. However, elevating the applied potential raised the desorption current, ${ }^{35}$ promoting better desorption and resulting in enhanced Pd concentration in the concentrate solution.
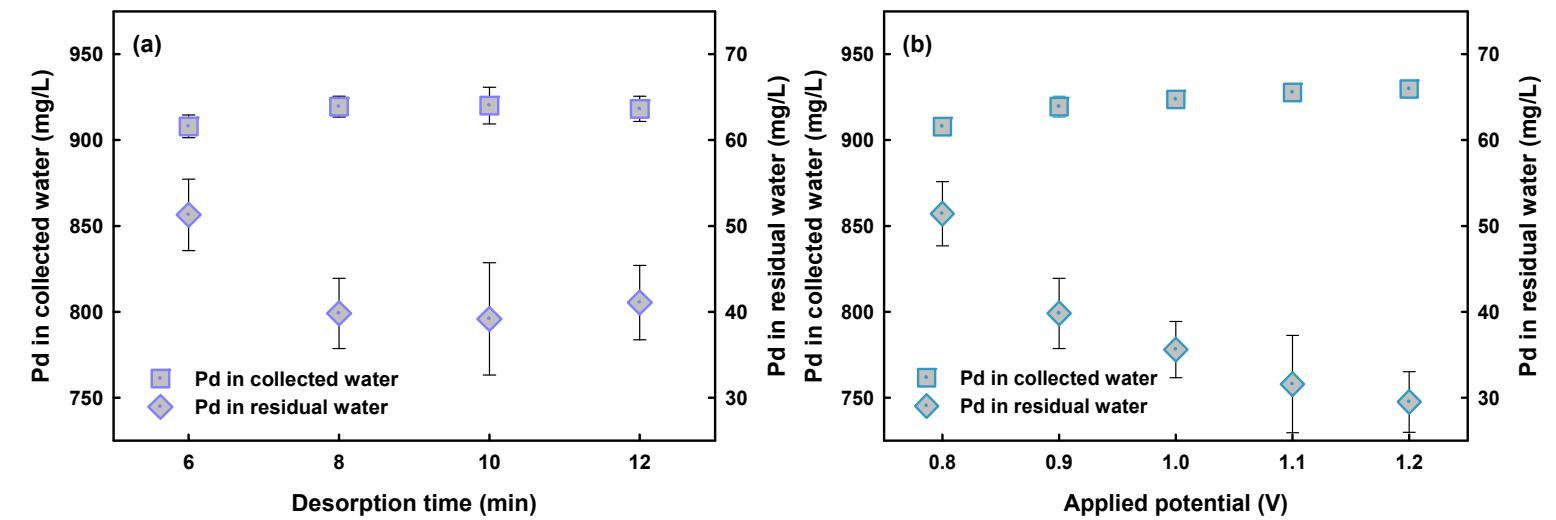

Figure 6. The enhanced concentration of Pd concentrate and the corresponding concentration of Pd in residual solutions after secondary desorption with increased (a) desorption time and (b) applied potential. The secondary desorption to release residual Pd ions from the carbon electrode was performed at $0.9 \mathrm{~V}$ and $8 \mathrm{~min}$.

\section{Deterioration of Pd adsorption performance under longer operation cycles}

During the MCDI operation with five cycles, it was shown earlier that the adsorbed Pd ions 
were not completely released from the carbon electrode in the primary desorption phase and additional desorption steps were employed in each cycle during the five cycles MCDI operation. Therefore the change of adsorptive capacity of the carbon electrode was investigated in terms of much longer cycles of ten cycles in total. The longer MCDI operation was carried out with adsorption at $0.9 \mathrm{~V}$ for $8 \mathrm{~min}$ using the initial feed of $100 \mathrm{mg} / \mathrm{L} \mathrm{Pd}$ solution, whereas the primary desorption process was performed at $-0.9 \mathrm{~V}$ for 8 min followed by a further desorption phase at $-1.2 \mathrm{~V}$ for $20 \mathrm{~min}$. No discharge of ions after those two desorption phases were confirmed in each cycle.

Figure 7 exhibits the Pd removal in each MCDI cycle. The Pd removal gradually decreased from $99.78 \%(12.17 \mathrm{mg} / \mathrm{g})$ to $98.04 \%(11.96 \mathrm{mg} / \mathrm{g})$ in the $10^{\text {th }}$ cycle. Although this is a margnial decrease of only $1.74 \%$ in 10 cycles and does not appear to be significant, it should be a concern for the long-term operation of MCDI for Pd recovery as this indicates an average $0.17 \%$ decrease in the removal for every cycle. If this decreasing trend shown in Figure 7 is to continue, it seems likely that the removal in MCDI will reach zero after 555 cycles of operations, which is not at all desirable. This decrease in Pd removal is likely attributed to physisorption of $\mathrm{Pd}$ ions within the porous structure of carbon electrode instead of electrosorption. In common with the adsorption behavior of other metal ions such as $\mathrm{Cd}^{2+}, \mathrm{Pb}^{2+}$ and $\mathrm{Cr}^{3+}$ on activated carbon, the adsorption of Pd ions on carbon electrode surface would be governed by a complicated adsorption process involving complex formation and surface adsorption mechanisms. ${ }^{36}$ The $\mathrm{Pd}$ ions in the aqueous solution migrate into the pores and interact with the interior carbon surface of pores. ${ }^{49}$ Those ions that are physically adsorbed and especially within the inner pores of porous carbon electrode are not likely to be easily detached by simply reversing the charges, resulting in reduced available surface area of carbon electrode for further adsorption. ${ }^{50}$ 


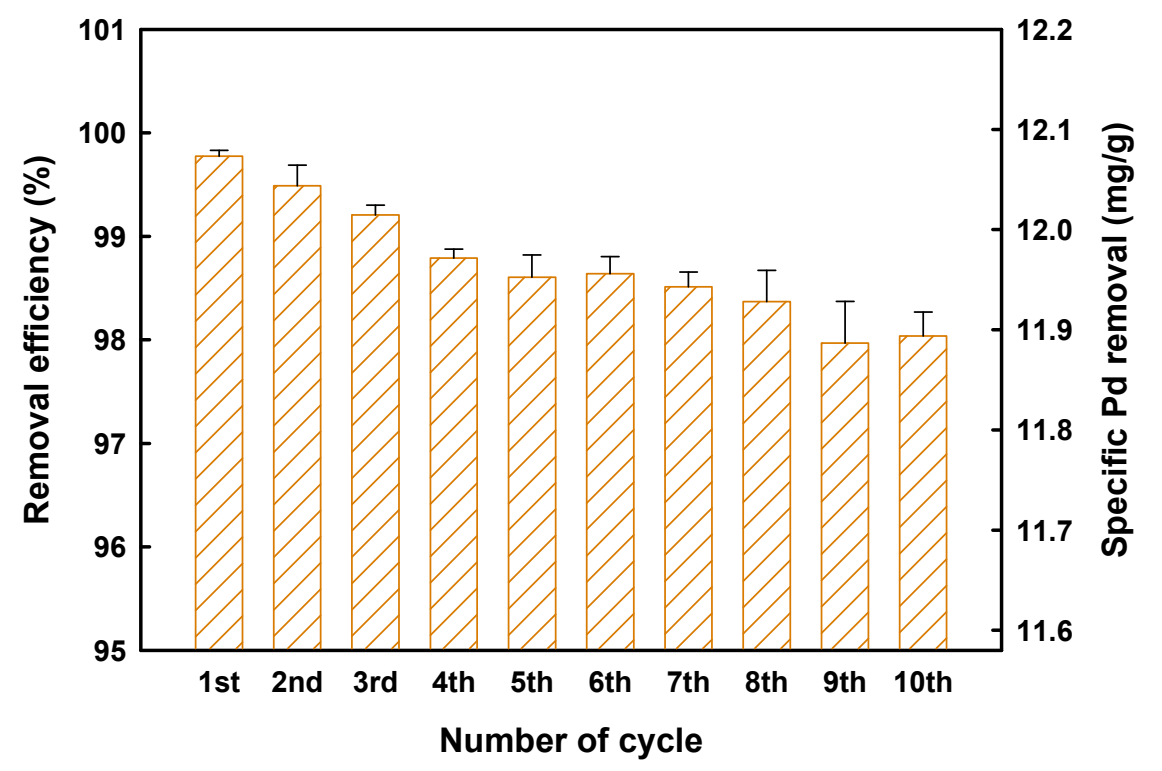

Figure 7. Pd removal from catalyst solution for ten cycles.

Both the cation exchange membrane and carbon cathode were analyzed by SEM and EDS after the ten cycles of operation to further observe their possible physical deterioration due to repetitive operations. Figure $8 \mathrm{c}$ shows that several deposits were found attached including metallic crystals on the cation exchange membrane. The EDS results in Figure 8c and d confirm the presence of Pd crystals. These results show that the decline in the MCDI performances was also likely due to $\mathrm{Pd}$ complexation or crystal formation on both the cathode and cation exchange membrane. 

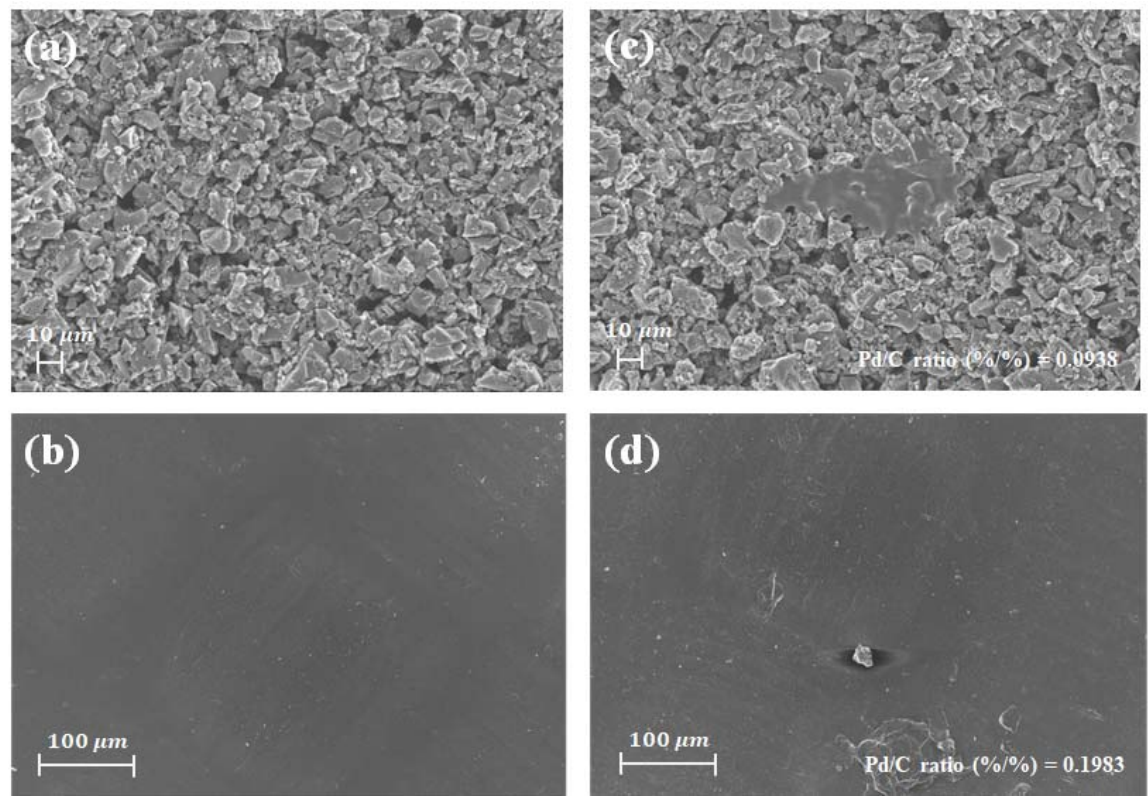

Figure 8. SEM images of virgin (a) carbon cathode and (b) cation exchange membrane, and used (c) carbon cathode and (d) cation exchange membrane after ten cycles MCDI test. Plus, the $\mathrm{Pd} / \mathrm{C}$ ratio described in this figure was measured by EDS analysis.

\section{Potential integration of MCDI and ion selective electrode for Pd recovery}

Electrowinning, one of the most widely used Pd recovery process from wastewaters, is still regarded as an energy-intensive technology. Especially its energy-efficiency is critically low for water sources with very low Pd concentrations, and because of this reason, the wastewater containing low $\mathrm{Pd}$ concentrations is rather disposed. However as shown in Figure 9a, integrating MCDI with the existing electrowinning process is expected to supplement the technology for concentrating $\mathrm{Pd}$ ions in the wastewater. This integrated process could be feasible due to the energy-efficiency of MCDI and enhanced recovery rate of Pd species. Besides, we can anticipate a more compact Pd recovery process consisting of MCDI only using a Pd selective electrode as presented in Figure $9 \mathrm{~b}$ which could significantly enhance the energy efficiency of the Pd concentration. 
(a)

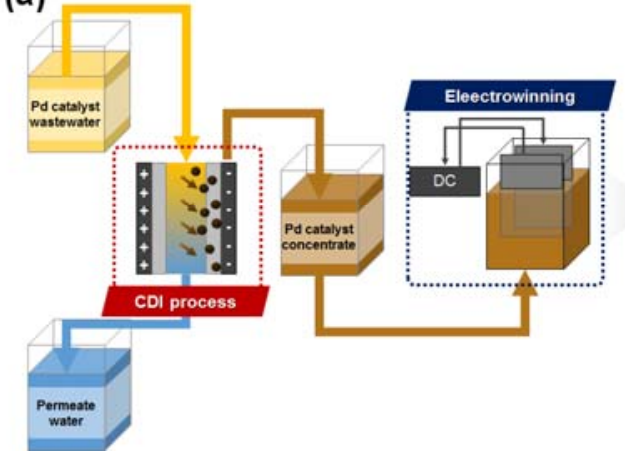

(b)

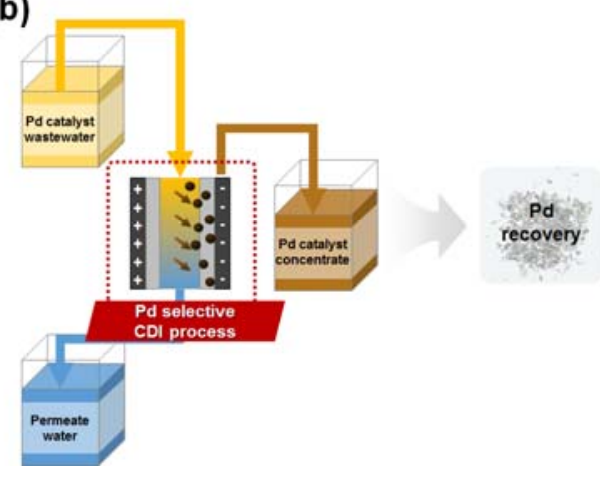

Figure 9. Possible application of MCDI: (a) an integrated Pd recovery process consisting of MCDI and electrowinning, and (b) single MCDI process using a Pd selective electrode material.

\section{Conclusions}

The potential of MCDI for the recovery of Pd from Pd catalyst wastewater from plating industry has been explored under various operating conditions and solution compositions, and the issues to be overcome are addressed in this work. The performances were measured in terms of the adsorptive and desorptive behavior during multiple cycles of MCDI operations for enrichment of the Pd concentrate. The following are the major findings from this lab-scale study:

- Through adequate process optimization such as operation time and applied potential for a fixed electrode mass, MCDI can be quite effective in the Pd removal from plating wastewater containing relatively high Pd concentration for its recovery and reuse.

- It was demonstrated that Pd can be significantly concentrated through successive cycles of MCDI operation by accumulatively desorbing the ions onto the Pd concentrate. However, as the concentrate solution becomes saturated with ions as adsorption cycles are performed repeatedly, incomplete discharge of $\mathrm{Pd}$ ions from the electrodes during the primary desorption phase was observed. Applying higher reverse potential slightly enhanced the desorption efficiency and hence its ability to concentrate the recovered Pd from the feed water. This unwelcoming effect is concerned to lead this process into unfeasible Pd recovery especially using very low Pd concentration wasetwaters such as $1 \mathrm{mg} / \mathrm{L}$ of $\mathrm{Pd}$.

- The electrosorptive capacity of the MCDI electrode decreased with the increase in the number of operation cycles because of the likely physical adsorption of Pd ions that cannot 
be easily released by reversing polarity of the carbon electrodes. SEM and EDS analysis further indicted the formation of a complex or crystal on both surfaces of cathode and cation exchange membrane which may be mitigated through proper physical and chemical cleanings.

- The study pointed out the potential for MCDI to be either integrated with the conventional electrowinning process to supplement Pd recovery from the plating industry. The other option is to apply MCDI using Pd ion selective electrode or ion-exchange membrane which could significantly enhance the MCDI energy efficiency.

\section{Acknowledgement}

This work is supported by the Korea Agency for Infrastructure Technology Advancement (KAIA) grant funded by the Ministry of Land, Infrastructure and Transport (17IFIP-B11695202). Support was also provided to HKS by the Australian Research Council (ARC) through Future Fellowship (FT140101208) and to SP under the UTS Chancellor's postdoctoral research fellowship.

\section{References}

1. Yazici, E.; Deveci, H., Recovery of metals from E-wastes. Madencilik 2009, 48 (3), 3-18.

2. Cui, J.; Zhang, L., Metallurgical recovery of metals from electronic waste: A review. J. Hazard. Mater. 2008, 158 (2), 228-256.

3. EU, Directive 2002/96/EC of the European parliament and of the council of 27 January 2003 on waste electrical and electronic equipment (WEEE) - joint declaration of the European parliament, the council and the commission relating to article 9. Official Journal L 037, 13/02/2003 2002.

4. Pillai, K. C.; Chung, S. J.; Moon, I. S., Studies on electrochemical recovery of silver from simulated waste water from $\mathrm{Ag}$ (II)/Ag (I) based mediated electrochemical oxidation process. Chemosphere 2008, 73 (9), 1505-1511.

5. Chen, J. P.; Lim, L., Recovery of precious metals by an electrochemical deposition method. Chemosphere 2005, 60 (10), 1384-1392.

6. Behnamfard, A.; Salarirad, M. M.; Veglio, F., Process development for recovery of copper and precious metals from waste printed circuit boards with emphasize on palladium and gold leaching and precipitation. Waste Manag. 2013, 33 (11), 2354-2363.

7. Awual, M. R.; Yaita, T.; El-Safty, S. A.; Shiwaku, H.; Okamoto, Y.; Suzuki, S., Investigation of palladium (II) detection and recovery using ligand modified conjugate adsorbent. Chem. Eng. J. 2013, 222, 
172-179.

8. Awual, M. R.; Hasan, M. M.; Znad, H., Organic-inorganic based nano-conjugate adsorbent for selective palladium (II) detection, separation and recovery. Chem. Eng. J. 2015, 259, 611-619.

9. Nikoloski, A. N.; Ang, K. L.; Li, D., Recovery of platinum, palladium and rhodium from acidic chloride leach solution using ion exchange resins. Hydrometallurgy 2015, 152, 20-32.

10. Zhao, R.; Porada, S.; Biesheuvel, P.; Van der Wal, A., Energy consumption in membrane capacitive deionization for different water recoveries and flow rates, and comparison with reverse osmosis. Desalination 2013, 330, 35-41.

11. Porada, S.; Zhao, R.; Van Der Wal, A.; Presser, V.; Biesheuvel, P., Review on the science and technology of water desalination by capacitive deionization. Prog. Mater. Sci. 2013, 58 (8), 13881442.

12. Suss, M.; Porada, S.; Sun, X.; Biesheuvel, P.; Yoon, J.; Presser, V., Water desalination via capacitive deionization: what is it and what can we expect from it? Energ. Environ. Sci. 2015, 8 (8), 2296-2319. 13. Wang, L.; Yu, F.; Ma, J., Design and Construction of Graphene-Based Electrode Materials for Capacitive Deionization. Acta Phys.-Chimica Sin. 2017, 33 (7), 1338-1353.

14. Liu, Y.; Nie, C.; Liu, X.; Xu, X.; Sun, Z.; Pan, L., Review on carbon-based composite materials for capacitive deionization. RSC Adv. 2015, 5 (20), 15205-15225.

15. Wang, Z;; Gong, H.; Zhang, Y.; Liang, P.; Wang, K., Nitrogen recovery from low-strength wastewater by combined membrane capacitive deionization (MCDI) and ion exchange (IE) process. Chem. Eng. J. 2017, 316, 1-6.

16. Tang, W.; Kovalsky, P.; He, D.; Waite, T. D., Fluoride and nitrate removal from brackish groundwaters by batch-mode capacitive deionization. Water Res. 2015, 84, 342-349.

17. Yeo, J. H.; Choi, J. H., Enhancement of nitrate removal from a solution of mixed nitrate, chloride and sulfate ions using a nitrate-selective carbon electrode. Desalination 2013, 320, 10-16.

18. Kim, Y. J.; Choi, J. H., Selective removal of nitrate ion using a novel composite carbon electrode in capacitive deionization. Water Res. 2012, 46 (18), 6033-6039.

19. Kim, Y. J.; Kim, J. H.; Choi, J. H., Selective removal of nitrate ions by controlling the applied current in membrane capacitive deionization (MCDI). J. Membr. Sci. 2013, 429, 52-57.

20. Huang, G. H.; Chen, T. C.; Hsu, S. F.; Huang, Y. H.; Chuang, S. H., Capacitive deionization (CDI) for removal of phosphate from aqueous solution. Desalin. Water Treat. 2014, 52 (4-6), 759-765.

21. Macías, C.; Lavela, P.; Rasines, G.; Zafra, M.; Tirado, J.; Ania, C., Improved electro-assisted removal of phosphates and nitrates using mesoporous carbon aerogels with controlled porosity. J. Appl. Electrochem. 2014, 44 (8), 963-976.

22. Huang, S. Y.; Fan, C. S.; Hou, C. H., Electro-enhanced removal of copper ions from aqueous solutions by capacitive deionization. J. Hazard. Mater. 2014, 278, 8-15.

23. Huang, C. C.; He, J. C., Electrosorptive removal of copper ions from wastewater by using ordered mesoporous carbon electrodes. Chem. Eng. J. 2013, 221, 469-475.

24. Ryu, T.; Ryu, J. C.; Shin, J.; Lee, D. H.; Kim, Y. H.; Chung, K.-S., Recovery of lithium by an electrostatic field-assisted desorption process. Ind. Eng. Chem. Res. 2013, 52 (38), 13738-13742. 
25. Ryu, T.; Lee, D.-H.; Ryu, J. C.; Shin, J.; Chung, K.-S.; Kim, Y. H., Lithium recovery system using electrostatic field assistance. Hydrometallurgy 2015, 151, 78-83.

26. Kim, S.; Yoon, H.; Shin, D.; Lee, J.; Yoon, J., Electrochemical selective ion separation in capacitive deionization with sodium manganese oxide. J. Colloid Interface Sci. 2017, 506, 644-648.

27. Wang, $\mathrm{H}_{\text {.; }} \mathrm{Na}, \mathrm{C}$., Binder-free carbon nanotube electrode for electrochemical removal of chromium. ACS Appl. Mater. Interfaces 2014, 6 (22), 20309-20316.

28. Yang, L.; Shi, Z.; Yang, W., Enhanced capacitive deionization of lead ions using air-plasma treated carbon nanotube electrode. Surf. Coat. Technol. 2014, 251, 122-127.

29. Tilton, J. E., Assessing the threat of mineral depletion. Miner. Energy-Raw Mater. Rep. 2003, 18 (1), 33-42.

30. Prior, T.; Giurco, D.; Mudd, G.; Mason, L.; Behrisch, J., Resource depletion, peak minerals and the implications for sustainable resource management. Glob. Environ. Change 2012, 22 (3), 577-587.

31. Penuelas, J.; Poulter, B.; Sardans, J.; Ciais, P.; Van Der Velde, M.; Bopp, L.; Boucher, O.; Godderis, Y.; Hinsinger, P.; Llusia, J., Human-induced nitrogen-phosphorus imbalances alter natural and managed ecosystems across the globe. Nat. Commun. 2013, 4.

32. Biesheuvel, P.; Van der Wal, A., Membrane capacitive deionization. J. Membr. Sci. 2010, 346 (2), 256-262.

33. Tang, W.; He, D.; Zhang, C.; Kovalsky, P.; Waite, T. D., Comparison of Faradaic reactions in capacitive deionization (CDI) and membrane capacitive deionization (MCDI) water treatment processes. Water Res. 2017, 120, 229-237.

34. Choi, J.; Lee, H.; Hong, S., Capacitive deionization (CDI) integrated with monovalent cation selective membrane for producing divalent cation-rich solution. Desalination 2016, 400, 38-46.

35. Lee, J. H.; Bae, W. S.; Choi, J. H., Electrode reactions and adsorption/desorption performance related to the applied potential in a capacitive deionization process. Desalination 2010, 258 (1), 159-163.

36. Huang, Z.; Lu, L.; Cai, Z.; Ren, Z. J., Individual and competitive removal of heavy metals using capacitive deionization. J. Hazard. Mater. 2016, 302, 323-331.

37. Zhao, R.; Satpradit, O.; Rijnaarts, H.; Biesheuvel, P.; Van der Wal, A., Optimization of salt adsorption rate in membrane capacitive deionization. Water Res. 2013, 47 (5), 1941-1952.

38. Mossad, M.; Zou, L., A study of the capacitive deionisation performance under various operational conditions. J. Hazard. Mater. 2012, 213, 491-497.

39. Xu, P.; Drewes, J. E.; Heil, D.; Wang, G., Treatment of brackish produced water using carbon aerogel-based capacitive deionization technology. Water Res. 2008, 42 (10), 2605-2617.

40. Hou, C. H.; Huang, C. Y., A comparative study of electrosorption selectivity of ions by activated carbon electrodes in capacitive deionization. Desalination 2013, 314, 124-129.

41. Elimelech, M.; Gregory, J.; Jia, X., Particle deposition and aggregation: measurement, modelling and simulation. Butterworth-Heinemann: 2013.

42. Cohen, I.; Avraham, E.; Bouhadana, Y.; Soffer, A.; Aurbach, D., Long term stability of capacitive deionization processes for water desalination: the challenge of positive electrodes corrosion. 
Electrochim. Acta 2013, 106, 91-100.

43. Avraham, E.; Noked, M.; Bouhadana, Y.; Soffer, A.; Aurbach, D., Limitations of charge efficiency in capacitive deionization processes III: The behavior of surface oxidized activated carbon electrodes. Electrochim. Acta 2010, 56 (1), 441-447.

44. Delahay, P., Double layer and electrode kinetics. John Wiley \& Sons Inc: 1965.

45. Oren, Y., Capacitive deionization (CDI) for desalination and water treatment-past, present and future (a review). Desalination 2008, 228 (1-3), 10-29.

46. Zhao, R.; Biesheuvel, P.; Miedema, H.; Bruning, H.; Van der Wal, A., Charge efficiency: a functional tool to probe the double-layer structure inside of porous electrodes and application in the modeling of capacitive deionization. J. Phys. Chem. Lett. 2009, 1 (1), 205-210.

47. Barka, N.; Abdennouri, M.; El Makhfouk, M.; Qourzal, S., Biosorption characteristics of cadmium and lead onto eco-friendly dried cactus (Opuntia ficus indica) cladodes. J. Environ. Chem. Eng. 2013, 1 (3), 144-149.

48. Yao, Q.; Tang, H. L., Effect of Desorption Methods on Electrode Regeneration Performance of Capacitive Deionization. J. Environ. Eng. 2017, 143 (9), 04017047.

49. Corapcioglu, M.; Huang, C., The adsorption of heavy metals onto hydrous activated carbon. Water Res. 1987, 21 (9), 1031-1044.

50. Namasivayam, C.; Kadirvelu, K., Agricultural solid wastes for the removal of heavy metals: adsorption of Cu (II) by coirpith carbon. Chemosphere 1997, 34 (2), 377-399. 
